\title{
Development of a genetic linkage map for Sharon goatgrass (Aegilops sharonensis) and mapping of a leaf rust resistance gene
}

\author{
P.D. Olivera, A. Kilian, P. Wenzl, and B.J. Steffenson
}

\begin{abstract}
Aegilops sharonensis (Sharon goatgrass), a diploid wheat relative, is known to be a rich source of disease resistance genes for wheat improvement. To facilitate the transfer of these genes into wheat, information on their chromosomal location is important. A genetic linkage map of Ae. sharonensis was constructed based on $179 \mathrm{~F}_{2}$ plants derived from a cross between accessions resistant (1644) and susceptible (1193) to wheat leaf rust. The linkage map was based on 389 markers (377 Diversity Arrays Technology (DArT) and 12 simple sequence repeat (SSR) loci) and was comprised of 10 linkage groups, ranging from 2.3 to $124.6 \mathrm{cM}$. The total genetic length of the map was $818.0 \mathrm{cM}$, with an average interval distance between markers of $3.63 \mathrm{cM}$. Based on the chromosomal location of 115 markers previously mapped in wheat, the four linkage groups of A, B, C, and E were assigned to Ae. sharonensis ( $\mathrm{S}^{\text {sh }}$ ) and homoeologous wheat chromosomes 6,1,3, and 2. The single dominant gene (designated LrAeSh1644) conferring resistance to leaf rust race THBJ in accession 1644 was positioned on linkage group A (chromosome $6 \mathrm{~S}^{\text {sh }}$ ) and was flanked by DArT markers wpt-9881 (at $1.9 \mathrm{cM}$ distal from the gene) and wpt-6925 (4.5 cM proximal). This study clearly demonstrates the utility of DArT for genotyping uncharacterized species and tagging resistance genes where pertinent genomic information is lacking.
\end{abstract}

Key words: Aegilops sharonensis, genetic linkage map, wheat leaf rust, resistance gene.

Résumé : L'Aegilops sharonensis (l'égilope de Sharon), une espèce diploïde apparentée au blé, est connue pour être une riche source de gènes de résistance aux ravageurs et, de ce fait, s'avère utile en amélioration génétique du blé. Pour faciliter le transfert de ces gènes au blé, des informations sur leur localisation chromosomique serait importante. Une carte génétique de l'Ae. sharonensis a été produite à l'aide de 179 plantes $\mathrm{F}_{2}$ issues d'un croisement entre des accessions résistante (1644) et sensible (1193) à la rouille brune. La carte génétique compte 389 marqueurs [ 377 marqueurs DArT (Diversity Array Technology) et 12 microsatellites (SSR)] répartis sur 10 groupes de liaison dont la taille varie entre 2,3 et 124,6 cM. La longueur totale de la carte est de $818,0 \mathrm{cM}$ et la distance moyenne entre les marqueurs est de 3,63 cM. Sur la base des positions chromosomiques connues pour 115 marqueurs déjà localisés chez le blé, les groupes de liaison $\mathrm{A}, \mathrm{B}, \mathrm{C}$ et $\mathrm{E}$ ont été assignés aux chromosomes 6, 1, 3 et 2 de l'Ae. sharonensis $\left(\mathrm{S}^{\mathrm{sh}}\right)$ et sont homéologues aux chromosomes correspondants chez le blé. Un seul gène dominant (nommé LrAeSh1644) conférant la résistance à la race THBJ de la rouille brune chez l'accession 1644 a été placé sur le groupe de liaison $\mathrm{A}$ (chromosome $6 \mathrm{~S}^{\text {sh }}$ ) et il était bordé des marqueurs DArT wpt-9881 (à 1,9 cM en distal du gène) et wpt-6925 (4,5 cM en proximal). Cette étude montre clairement l'intérêt des marqueurs DArT pour le génotypage chez des espèces peu caractérisées et pour marquer des gènes de résistance lorsque les informations génomiques pertinentes n'existent pas. [Traduit par la Rédaction]

Mots-clés : Aegilops sharonensis, carte génétique, rouille brune du blé, gène de résistance.

\section{Introduction}

Wheat leaf rust, caused by Puccinia triticina Eriks., is one of the most important diseases of wheat (Triticum aestivum L.) worldwide. It is the most widely distributed of all wheat rusts and has been prevalent in many durum and bread wheat producing areas (Kolmer 2005). The leaf rust pathogen is quite variable, as its populations are comprised of many different virulence types. In North America alone, between 40 and 60 races are identified every year (Kolmer et al. 2004; Kolmer 2005). The use of resistant cultivars to control leaf rust requires the availability of many sources of resistance to counter the frequent appearance of new virulence types in the pathogen populations. Wild relatives of wheat are an important gene reservoir for resistance to wheat diseases and offer a diverse source of unique alleles for wheat improvement. These unique resistance alleles are an important source of genetic diversity for countering virulence shifts in pathogen populations. For example, many genes for resistance to leaf rust ( $\operatorname{Lr} 9, \operatorname{Lr} 21, \operatorname{Lr} 22$, Lr28, Lr35, Lr39, Lr42, Lr47, Lr51, Lr56, Lr57, Lr58, Lr59, and Lr62) have been introgressed from Aegilops (McCallum et al. 2012), the closest related genus to Triticum (Kimber and Feldman 1987).

Aegilops sharonensis Eig (common name: Sharon goatgrass) is a wild relative of wheat that is endemic to the coastal plain of Israel and southern Lebanon (van Slageren 1994). The species belongs to the secondary genepool of wheat and carries the $S^{1}$ or $S^{\text {sh }}$ genome, which is homoeologous to the B genome of wheat (Friebe and Gill 1996). Aegilops sharonensis is a rich source of genes for disease and insect resistance. Previous investigators have identified accessions with resistance to many pathogens and pests, including leaf rust, stem rust, stripe rust, powdery mildew, and Karnal bunt (Gill et al. 1985; Warham et al. 1986; Manisterski et al. 1988; Anikster et al. 2005), and Hessian fly and greenbug (Gill et al. 1985). The potential for increasing the diversity of disease resistance in wheat with genes from Ae. sharonensis is great, as Olivera et al. (2007) recently identified many accessions with resistance to the important wheat diseases of leaf rust, stem rust, stripe rust, powdery mildew, spot blotch, and tan spot. In another recent study,

Received 10 April 2013. Accepted 17 July 2013.

Corresponding Editor: C.L. McIntyre.

P.D. Olivera and B.J. Steffenson. Department of Plant Pathology, University of Minnesota, St. Paul, MN 55108, USA.

A. Kilian and P. Wenzl. Diversity Arrays P/L, 1 Wilf Crane Crescent, Yarralumla, Canberra, ACT 2600, Australia.

Corresponding author: P.D. Olivera (e-mail: oliv0132@umn.edu). 
Table 1. Disease reaction of parents and $\mathrm{F}_{1}$ plants to leaf rust and segregation of $\mathrm{F}_{2}$ plants and $\mathrm{F}_{3}$ families from a cross between Aegilops sharonensis accessions 1193 and 1644 to leaf rust.

\begin{tabular}{|c|c|c|c|c|c|c|c|c|c|c|c|c|c|c|c|}
\hline & \multicolumn{2}{|c|}{ Parents } & \multicolumn{2}{|c|}{$\mathrm{F}_{1}$ plants } & \multicolumn{5}{|c|}{ Segregation of $\mathrm{F}_{2}$ plants } & \multicolumn{6}{|c|}{$\underline{\text { Segregation of } \mathrm{F}_{3} \text { families }}$} \\
\hline & 1193 & 1644 & $\begin{array}{l}\text { No. of } \\
\text { plants }\end{array}$ & IT & $R$ & $S$ & $\begin{array}{l}\text { Ratio } \\
\text { tested }\end{array}$ & $\chi^{2}$ & $P$ & HR & Seg. & $\mathrm{HS}$ & $\begin{array}{l}\text { Ratio } \\
\text { tested }\end{array}$ & $\chi^{2}$ & $P$ \\
\hline Leaf rust race $\mathrm{THBJ}$ & 3 & $0 ; 1$ & 4 & $1-0$ & $139^{a}$ & $43^{a}$ & $3: 1$ & 0.190 & 0.663 & $45^{b}$ & $84^{b}$ & $40^{b}$ & $1: 2: 1$ & 0.302 & 0.860 \\
\hline
\end{tabular}

Note: Infection types (ITs) were based on the 0-4 rating scale of Long and Kolmer (1989). Plants exhibiting ITs of 0;, 1, and 2 were considered resistant, whereas those exhibiting ITs of 3 and 4 were considered susceptible. - and + indicates lower or higher sporulation for ITs than described in the original scale.

${ }^{a}$ Number of plants resistant $(R)$ or susceptible $(S)$ to leaf rust from a total of $182 \mathrm{~F}_{2}$ plants.

${ }^{b}$ Number of $\mathrm{F}_{3}$ families homozygous resistant (HR), segregating (Seg.), or homozygous susceptible (HS) to leaf rust.

Olivera et al. (2008) determined the genetic basis of resistance to wheat leaf rust, stem rust, and powdery mildew in Ae. sharonensis. They found that resistance to leaf rust (races THBJ and $\mathrm{BBBB}$ ) in $A$ e. sharonensis is conferred by a single gene with major effect. The simple inheritance of leaf rust resistance in Ae. sharonensis should simplify the transfer of resistance in wide crosses with wheat. In addition to elucidating the number and mode of action of genes controlling traits of interest in wild wheats, information about the chromosomal location of genes and linked markers can be useful for marker-assisted selection in gene introgression programs.

The advent of molecular marker technology has greatly facilitated the construction of genetic linkage maps and also the exploitation of useful genes from wild progenitor germplasm for cultivated crop improvement (Tanksley and McCouch 1997). Diversity Arrays Technology (DArT) has provided in the last decade an attractive and economical marker system for genotyping plant populations at medium to high density. DArT is a hybridizationbased technique that allows the simultaneous typing of several thousand loci in a single assay without previous sequence information (Jaccoud et al. 2001). This independence from sequence information was a very important attribute of DArT at the time when sequencing costs and throughputs were higher compared to nowadays. DArT markers have been applied for genetic mapping in a range of cereal crops, including rice (Jaccoud et al. 2001), barley (Wenzl et al. 2004), oats (Tinker et al. 2009), sorghum (Mace et al. 2008), and durum (Mantovani et al. 2008) and bread wheat (Semagn et al. 2006). A full list of nearly 100 organisms for which DArT has been developed and applied is available at http:// www.diversityarrays.com/genotypingserv.html. Microsatellites or simple sequence repeats (SSRs) are another valuable type of molecular marker. They have proven very useful in the identification and exploitation of valuable genes from wild relatives of cultivated species. SSRs have been used for the identification of introgressed regions of alien chromosomes in cultivated wheat (Marais et al. 2006; Miranda et al. 2006) and can be employed for the development of linkage maps in wild wheat relatives because of their high level of polymorphism, locus-specificity, and high level of transferability between species in the Triticeae (Plaschke et al. 1995; Gupta et al. 2002; Adonina et al. 2005).

The objectives of this study were to generate a genetic linkage map of Ae. sharonensis and use it to identify molecular markers linked to a gene conferring resistance to wheat leaf rust.

\section{Materials and methods}

\section{Plant materials}

Aegilops sharonensis accessions 1644 and 1193 (Table 1) were selected as parents for the mapping population because they exhibited differential reactions to wheat leaf rust (Olivera et al. 2007). Accession 1644 is resistant to leaf rust, whereas accession 1193 is susceptible. Accession 1644 was collected from Ashdod in the Philistean Coastal Plain of southern Israel, and accession 1193 was collected from Hefzi Bah in the Sharon Coastal Plain of central Israel. Crosses between 1644 and 1193 were made in 2004 using standard hybridization techniques and yielded four $F_{1}$ seeds. $F_{1}$ plants were grown in the greenhouse and selfed to produce $F_{2}$ populations. One hundred and eighty-two individual $\mathrm{F}_{2}$ plants were used for the disease evaluations and were then selfed to produce $F_{3}$ families. All spikes from $F_{1}$ and $F_{2}$ plants were bagged before anthesis to prevent any chance of cross-pollination.

\section{Pathogen race, plant growth conditions, inoculation protocols, and disease assessment}

The pathogen race used in this study was selected based on its differential virulence pattern on the parental accessions of Ae. sharonensis. Race THBJ of $P$. triticina has a wide spectrum of virulence and is a common race in the Great Plains of the United States (Long et al. 2002; Kolmer et al. 2004). Race THBJ was purified, verified for its virulence phenotype, and then increased on the susceptible wheat cultivar Thatcher (CI 10003). Plant growth and inoculation and disease assessment protocols were done as described by Olivera et al. (2007). $F_{2}$ plants and $F_{3}$ families were evaluated to leaf rust race THBJ as seedlings in the greenhouse to determine the inheritance of resistance based on phenotypic ratios. Twenty plants from each $\mathrm{F}_{3}$ family were screened to confirm the rust phenotype and genotype of $\mathrm{F}_{2}$ plants. According to Hanson (1958), this $F_{3}$ family size has a $99 \%$ probability of distinguishing between segregating and nonsegregating families for monogenic inheritance. Plants were evaluated for their infection types (Its) to leaf rust 12-13 days after inoculation based on the 0-4 scale of Long and Kolmer (1989). Progeny exhibiting ITs from 0 to 2 were considered resistant, and those exhibiting ITs from 3 to 4 were considered susceptible.

\section{DNA extraction, polymerase chain reaction (PCR), and genotyping with SSR and DArT markers}

Genomic DNA was extracted from each $\mathrm{F}_{2}$ plant for subsequent genotyping with SSR and DArT markers. DNA was extracted from the young tillers of 4- to 5-week-old plants using the CTAB method (Doyle and Doyle 1990). As the $1193 \times 1644$ population was developed before the advent of cost-effective platforms for SNP and GBS genotyping, SSR and DArT markers were used for map construction. One hundred wheat and barley SSR markers were evaluated for their transferability to the genome of Ae. sharonensis and presence of polymorphism between the parents of the mapping population. These microsatellites were from three different sources: the Institute of Plant Genetics and Crop Plant Research (IPK) in Gatersleben, Germany (Gatersleben Wheat Microsatellites or GWM), United States Department of Agriculture (USDA) in Beltsville, MD (Beltsville Agricultural Research Center or BARC microsatellites), and Scottish Crop Research Institute (SCRI) in Invergowrie, Scotland (SCRI microsatellites). GWM microsatellites were developed by Röder et al. (1998) and were selected based on their ability to amplify the genome of Ae. longissima (Adonina et al. 2005), the species most closely related to Ae. sharonensis (Friebe and Gill 1996). The BARC microsatellites were developed by Song et al. (2002) as part of the United States Wheat and Barley Scab Initiative's effort to tag loci contributing to Fusarium head blight resistance in wheat. The SCRI microsatellites were developed by Ramsay et al. (2000). Selected barley microsatellites were used for genotyping the Ae. sharonensis genome based on previous reports regarding 
the transferability of SSRs and EST-SSRs between Triticum and Hordeum species (Hernández et al. 2002; Varshney et al. 2005). In total, 13 wheat and 2 barley SSR markers were used for genotyping the $\mathrm{F}_{2}$ population. Due to the low quality of DNA from three progeny, genotyping and mapping were conducted on $179 \mathrm{~F}_{2}$ plants. The $5^{\prime}$ end of each forward SSR primer was tailed with the M13 forward sequencing primer (CACGACGTTGTAAAACGAC) (Oetting et al. 1995) for labeling the PCR product.

PCR amplification was performed in a $10 \mu \mathrm{L}$ volume reaction at a final concentration of $20 \mathrm{ng}$ genomic DNA, 1× PCR buffer (Fermentas, Glen Burnie, Md.), $1.6 \mathrm{mmol} / \mathrm{L}$ of $\mathrm{MgCl}_{2}, 200 \mu \mathrm{mol} / \mathrm{L}$ of dNTPs, $150 \mathrm{nmol} / \mathrm{L}$ of each $5^{\prime}$-tagged forward and reverse primer, 5.0 pmol of M13 labeled primer, and 0.5 U Taq polymerase (Applied Biosystems, Foster City, Calif.). The PCR for wheat microsatellites was carried out in an Eppendorf Mastercycler (Eppendorf AG, Hamburg, Germany) using the following program: 3 min at $94^{\circ} \mathrm{C}$, 45 cycles of $1 \mathrm{~min}$ at $94^{\circ} \mathrm{C}, 1 \mathrm{~min}$ at either 50,55 , or $60^{\circ} \mathrm{C}$ depending on the individual microsatellite, and a final extension of 10 min at $72{ }^{\circ} \mathrm{C}$ (Röder et al. 1998). PCR profiles for barley microsatellites are detailed in Ramsay et al. (2000). The amplification products were resolved on a $6.0 \%$ polyacrylamide gel in a LICOR 4200 DNA analyzer (LICOR Inc., Lincoln, Nebr.). An IR-labeled molecular weight standard (50-350 bases) ladder from LICOR was used for estimation of the amplicon sizes. The molecular weight of each DNA band was calculated by the SAGA GT Generation 2 software (LICOR).

DArT marker assays were conducted by Triticarte Pty. Ltd. (Yarralumla, Australia; http://www.triticarte.com.au) essentially as described by Akbari et al. (2006). Initially, the parents of the mapping population were evaluated for polymorphism with array-containing DArT markers developed from clone libraries originating from several Triticum and Aegilops species. Based on this initial evaluation, a genotyping array was constructed and used for the final genotyping of progeny. The final array contained 7680 clones with each clone printed as two replicate spots on the array. The array consisted mostly of 6528 clones (markers) selected for high density Genotyping Array version 2.6.2 of wheat developed in 2009 by Triticarte and more recently replaced by version 3.0 array (now available at Diversity Arrays Technology $\mathrm{P} / \mathrm{L}$, which offers DArT for nearly 100 species). This set of 6528 markers is based on the analysis of thousands of cultivated and wild wheat accessions and was selected for high polymorphism information content (PIC) values. In addition, the array contained 384 clones developed from flow-sorted wheat chromosome arm 1BS and 768 clones derived from flow-sorted chromosome 3B of several wheat accessions (Triticarte's unpublished data). Clones derived from the wheat $B$ genome were preferentially incorporated into the array given the homoeologous relationship between the Ae. sharonensis $\left(\mathrm{S}^{\mathrm{sh}}\right)$ and T. aestivum (B) genomes (Maestra and Naranjo 1997).

\section{Segregation analysis and map construction}

All markers were analyzed for their goodness-of-fit to the appropriate expected segregation ratios (i.e., 1:2:1, 1:3, or 3:1) using the chi-square $\left(\chi^{2}\right)$ test. Loci fitting the expected segregation ratio or those deviating significantly from the expected ratio at $p<0.05$ and $p<0.01$ were included in the analysis and subsequent linkage map. Loci with extreme distortion $(p<0.001)$ were not included in the map. Linkage groups were iteratively constructed using LOD scores ranging from 2.0 to 10.0 and were finally established using a minimum LOD score of 4.0. The genetic linkage map was generated by the program JoinMap version 4.0 (van Ooijen 2006), using the Kosambi mapping function (Kosambi 1943). The final map was drawn using the program MapChart version 2.1 (Voorrips 2002). When possible, linkage groups were assigned to Ae. sharonensis $\left(\mathrm{S}^{\mathrm{sh}}\right)$ and homoeologous wheat chromosomes based on the presence of markers with known chromosomal location in the B genome of T. aestivum.

\section{Results}

$\mathrm{F}_{1}$ plants of the cross between 1644 and 1193 exhibited ITs (range of 0 ; to 1-) to P. triticina that were similar to the resistant parent (1644) (Table 1). The derived $F_{2}$ population segregated in an approximate 3:1 ratio for resistant and susceptible plants, and in the $\mathrm{F}_{3}$ generation, the population segregated in an approximate 1:2:1 ratio for homozygous resistant : segregating : homozygous susceptible families (Table 1). These data indicate that leaf rust resistance in accession 1644 is controlled by a single dominant gene. The leaf rust resistance gene was given the provisional designation of LrAeSh1644, pending studies to elucidate its allelic relationship with previously described rust resistance loci.

Of the 100 evaluated microsatellites, only 15 exhibited polymorphism between the parents of the mapping population. A total of 542 polymorphic DArT markers were obtained from the selected arrays. In the final analysis, a total of 377 DArT and 12 SSR loci were integrated into the genetic map (Fig. 1). The genetic map includes seven large and three small linkage groups (LOD > 4.0), with a total length of $818.0 \mathrm{cM}$ (Table 2; Fig. 1). Individual linkage groups ranged from 2.3 (linkage group I) to $124.6 \mathrm{cM}$ (linkage group C) (Table 2). The average distance between markers was $3.63 \mathrm{cM}(2.52 \mathrm{cM}$ when linkage group J is excluded), and the largest interval between markers was $24.1 \mathrm{cM}$ (linkage group J) (Table 2). Gaps larger than $10 \mathrm{cM}$ were found in linkage groups A (15.8 and $13.2 \mathrm{cM}), \mathrm{C}(17.9 \mathrm{cM}), \mathrm{E}$ (11.3 and $16.8 \mathrm{cM})$, and $\mathrm{G}(13.8 \mathrm{cM})$. The map distance between two consecutive DArT markers was less than $0.5 \mathrm{cM}$ in $39 \%$ of the markers incorporated in the map (Fig. 2). Total number of loci per linkage group ranged from 3 (linkage groups I and J) to 85 (linkage group C) (Table 2; Fig. 1), with an average of 38.9 loci/linkage group.

The $\chi^{2}$ segregation test for each locus revealed significant segregation distortion for 142 markers (26.2\%). Fifty markers that deviated significantly from the expected ratio at $p<0.05$ and $p<0.01$ were incorporated into the genetic map (Table 2). Fortythree markers with a skewed segregation ratio at $p<0.05$ and $p<0.01$ favored alleles from parent 1193, whereas only seven markers exhibited distortion in favor of parent 1644. Loci with skewed segregation were found in 7 of the 10 linkage groups. Over $65 \%$ (33) of the markers exhibiting segregation distortion were positioned in linkage group C and covered $43 \%$ of its entire genetic length.

Based on the chromosomal location of 115 DArT and SSR markers previously mapped in wheat, four linkage groups were assigned to Ae. sharonensis $\left(\mathrm{S}^{\mathrm{sh}}\right)$ and homoeologous wheat chromosomes. Linkage group A included 11 DArT markers and one SSR marker (BARC146) from wheat chromosomes 6A, 6B, and 6D and two SSR markers (Bmac316 and Bmag0009) from barley chromosome $6 \mathrm{H}$. The high frequency and wide distribution of markers from wheat chromosomes $6 \mathrm{~A}, 6 \mathrm{~B}$, and $6 \mathrm{D}$ and barley chromosome $6 \mathrm{H}$ indicated assignment of this linkage group to chromosome $6 \mathrm{~S}^{\text {sh }}$ of Ae. sharonensis, which is homoeologous to wheat chromosome 6B. Linkage group B contained 10 DArT markers from wheat chromosome $1 \mathrm{~B}$ and five DArT markers from wheat chromosomes $1 \mathrm{~A}$ and $1 \mathrm{D}$. The predominance and extensive distribution of wheat chromosome $1 \mathrm{~B}$ markers indicated assignment of this linkage group to chromosome $1 S^{\text {sh }}$ of Ae. sharonensis, which is homoeologous to wheat chromosome $1 \mathrm{~B}$. Linkage group $\mathrm{C}$ included $17 \mathrm{DArT}$ markers and two microsatellite markers (BARC147 and Xgwm674) from wheat chromosome 3B and three DArT markers from wheat chromosome 7D. Again, the predominance and distribution of wheat chromosome $3 \mathrm{~B}$ markers indicated assignment of linkage group B to chromosome $3 S^{\text {sh }}$ of Ae. sharonensis, which is homoeologous to wheat chromosome 3B. Linkage group E included 15 DArT and four microsatellite (BARC095, BARC124, BARC159, and Xgwm210) markers from wheat chromosome 2B and three DArT markers from wheat chromosome $2 \mathrm{D}$. The predominance and extensive distribution of wheat chromosome $2 \mathrm{~B}$ markers indicated assignment of this linkage group to chromosome $2 S^{\text {sh }}$ of 
Fig. 1. Genetic linkage map of the Aegilops sharonensis $1193 \times 1644 \mathrm{~F}_{2}$ population based on 381 loci. Loci marked with * and ** deviated significantly from the expected ratio at $p<0.05$ and $p<0.01$, respectively. Cumulative map distances in centiMorgans (cM) are shown at the left side of the linkage groups with the loci names given at the right side. Loci with known chromosomal locations in the genomes of wheat are indicated in blue. The mapped leaf rust (LrAeSh1644) resistance gene is indicated in red.

\section{Linkage group A Linkage group B}

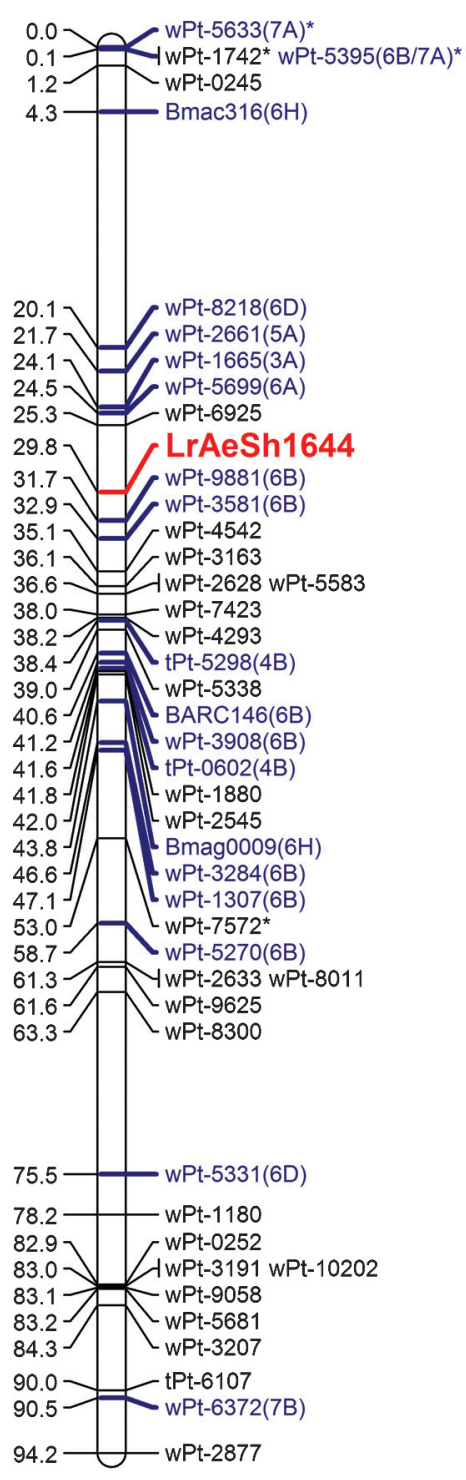

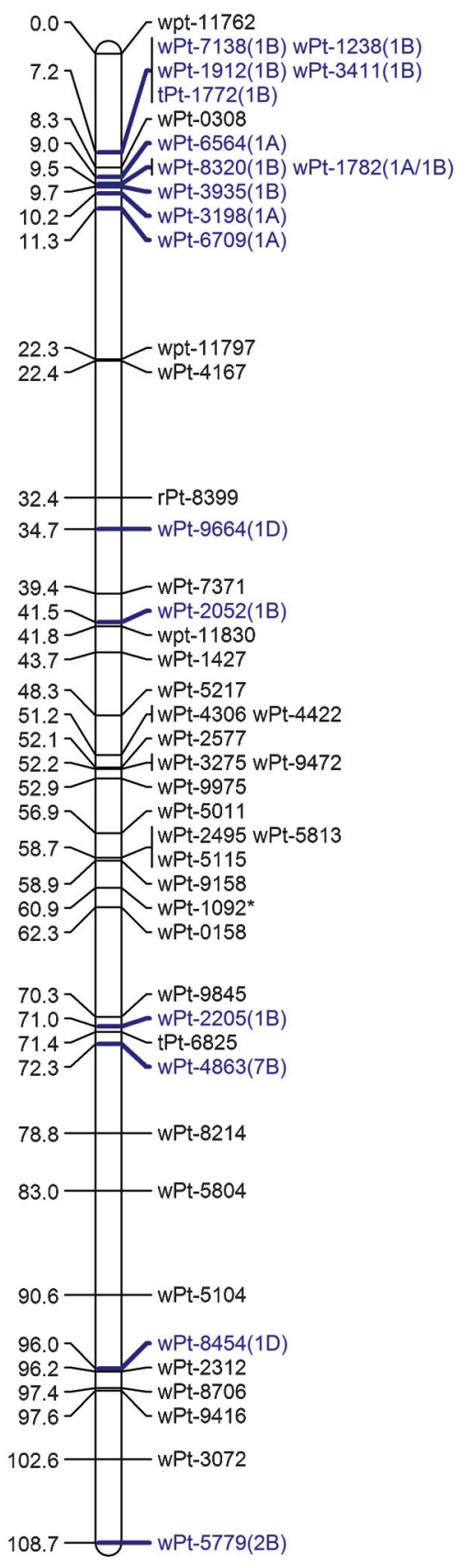

\section{Linkage group C}

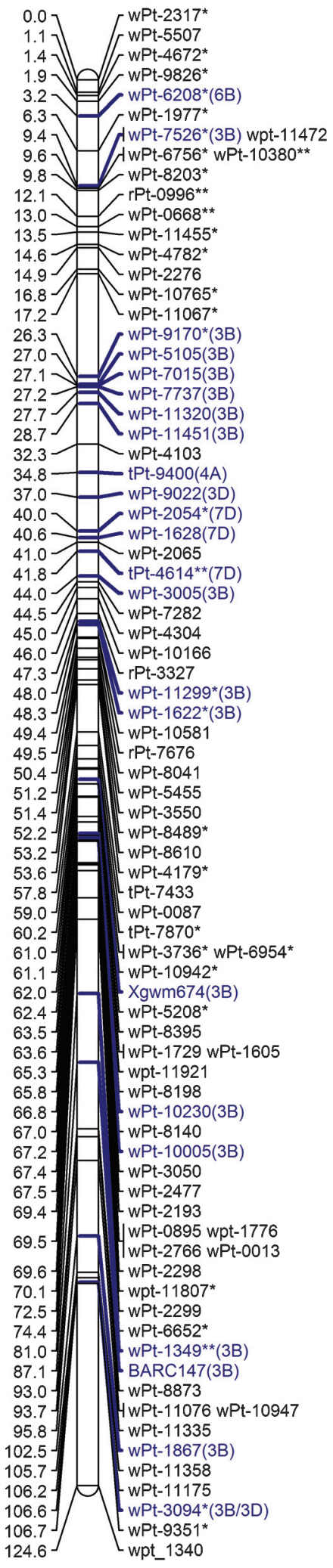


Fig. 1 (continued).

\section{Linkage group $D \quad$ Linkage group $E \quad$ Linkage group $F$}

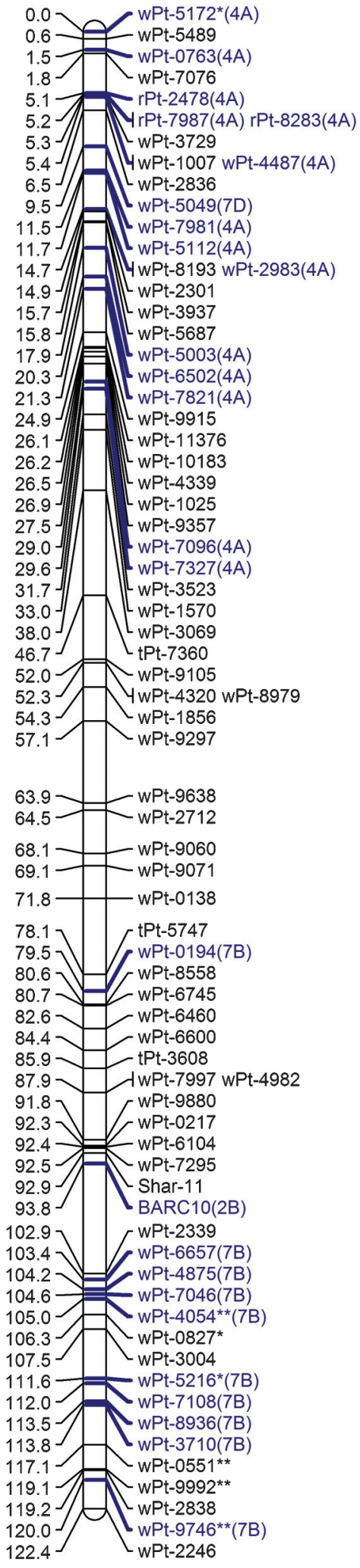

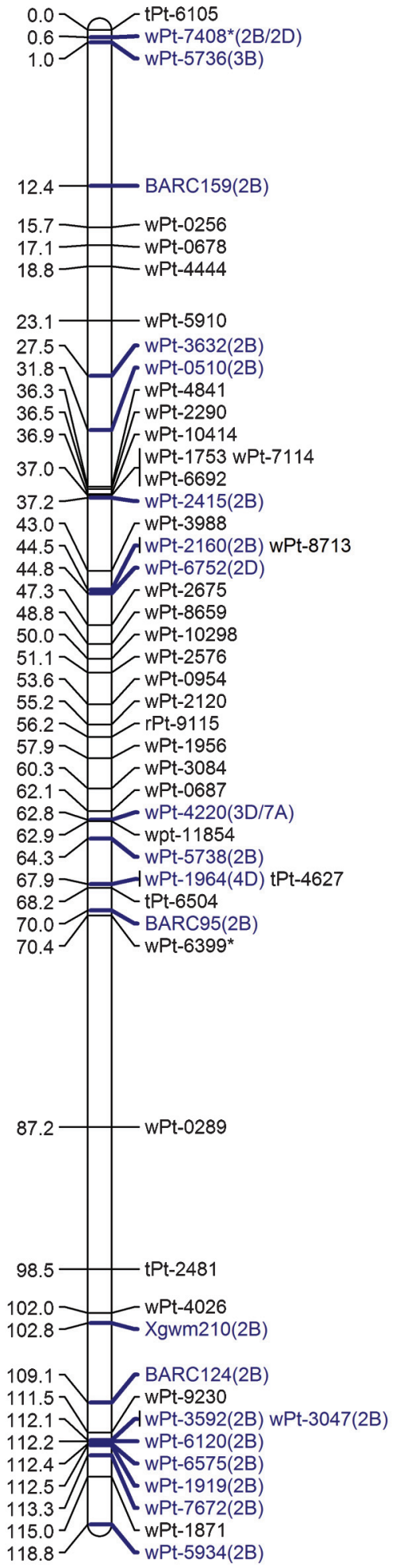

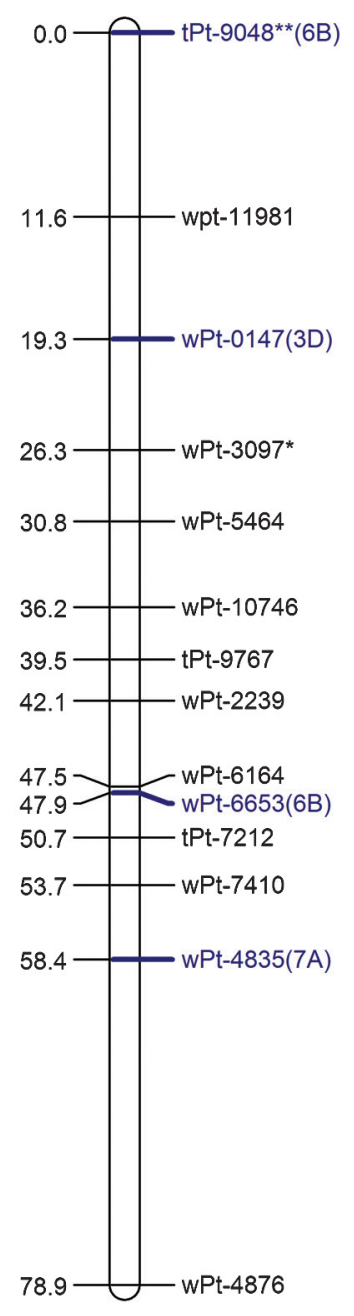


Fig. 1 (concluded).

\section{Linkage group $\mathrm{G} \quad$ Linkage group $\mathrm{H} \quad$ Linkage group I}

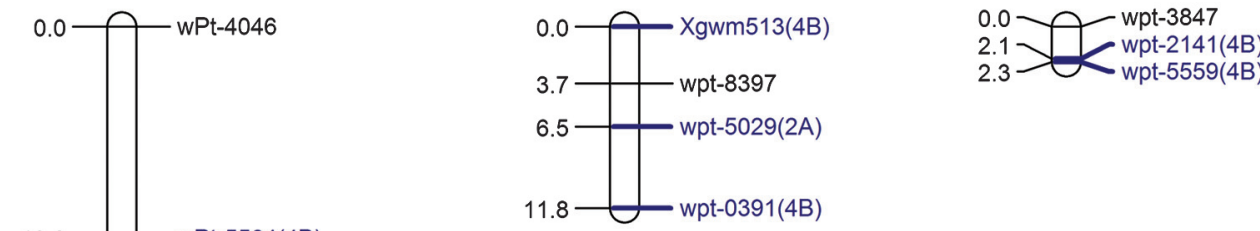

\section{Linkage group $\mathrm{J}$}

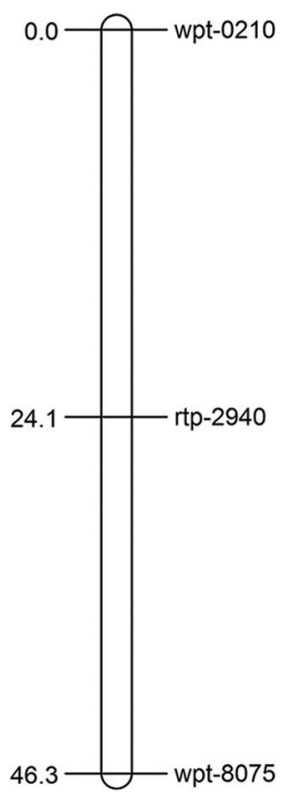

Ae. sharonensis, which is homoeologous to wheat chromosome $2 \mathrm{~B}$. The four remaining linkage groups included markers from different $\mathrm{B}$ genome chromosomes and (or) the A and D genomes of wheat (linkage groups D, F, G, and H) and could not be reliably assigned to specific Ae. sharonensis ( $\mathrm{S}^{\mathrm{sh}}$ ) chromosomes. In particular, the upper and lower "arms" of linkage group D contained sets of markers derived predominantly from two different wheat chromosomes. Eleven DArT markers from wheat chromosomes 7B and 7D and 14 DArT markers from wheat chromosome 4A were identified in linkage group D.
The gene LrAeSh1644 conferring resistance to leaf rust race THBJ was positioned on linkage group A and was flanked by DArT markers wpt-9881 (1.9 cM distal from the gene) and wpt-6925 (4.5 cM proximal).

\section{Discussion}

This work documents the first genetic linkage map constructed for Ae. sharonensis. Using DArT, together with anchoring SSR markers, a medium-density linkage map of 389 loci was constructed for Ae. sharonensis (Fig. 1) from previously developed arrays of wheat 
Table 2. Chromosomal assignment, number of loci mapped, map lengths, and average and maximum distance between loci for each of the 10 linkage groups identified in the cross between Aegilops sharonensis accessions 1193 and 1644 based on DArT and SSR markers.

\begin{tabular}{|c|c|c|c|c|c|c|}
\hline $\begin{array}{l}\text { Linkage } \\
\text { group }\end{array}$ & $\begin{array}{l}\text { Chromosome assigned } \\
\text { in Ae. sharonensis }\end{array}$ & $\begin{array}{l}\text { No. of loci } \\
\text { mapped }\end{array}$ & $\begin{array}{l}\text { Map } \\
\text { length }(\mathrm{cM})\end{array}$ & $\begin{array}{l}\text { Average distance } \\
\text { between loci (cM/loci) }\end{array}$ & $\begin{array}{l}\text { Maximum distance } \\
\text { between loci }(\mathrm{cM})\end{array}$ & $\begin{array}{l}\text { Markers with } \\
\text { segregation distortion }\end{array}$ \\
\hline A & $6 S^{s h}$ & 46 & 94.2 & 2.05 & 15.8 & 4 \\
\hline B & $1 S^{\text {sh }}$ & 49 & 108.7 & 2.22 & 11.0 & 1 \\
\hline $\mathrm{C}$ & $3 S^{s h}$ & 85 & 124.6 & 1.47 & 17.9 & 33 \\
\hline D & - & 75 & 122.4 & 1.63 & 9.1 & 7 \\
\hline $\mathrm{E}$ & $2 S^{\text {sh }}$ & 53 & 118.8 & 2.24 & 11.5 & 2 \\
\hline $\mathrm{F}$ & - & 14 & 78.9 & 5.54 & 20.5 & 1 \\
\hline G & - & 57 & 110.0 & 1.93 & 9.0 & 2 \\
\hline $\mathrm{H}$ & - & 4 & 11.8 & 2.95 & 5.3 & 0 \\
\hline I & - & 3 & 2.3 & 0.76 & 2.1 & 0 \\
\hline $\mathrm{J}$ & - & 3 & 46.3 & 15.4 & 24.1 & 0 \\
\hline Total & N/A & 389 & 818 & N/A & $\mathrm{N} / \mathrm{A}$ & 50 \\
\hline Average & N/A & 38.9 & 81.8 & 3.63 & N/A & 6.25 \\
\hline
\end{tabular}

Note: - , could not be assigned to a specific Ae. sharonensis chromosome; N/A, not applicable. ${ }^{a} p<0.01$.

Fig. 2. Distribution of Kosambi map distances between two consecutive DArT loci over all chromosomes based on the Aegilops sharonensis $\mathrm{F}_{2}$ population derived from the parental accessions 1193 and 1644.

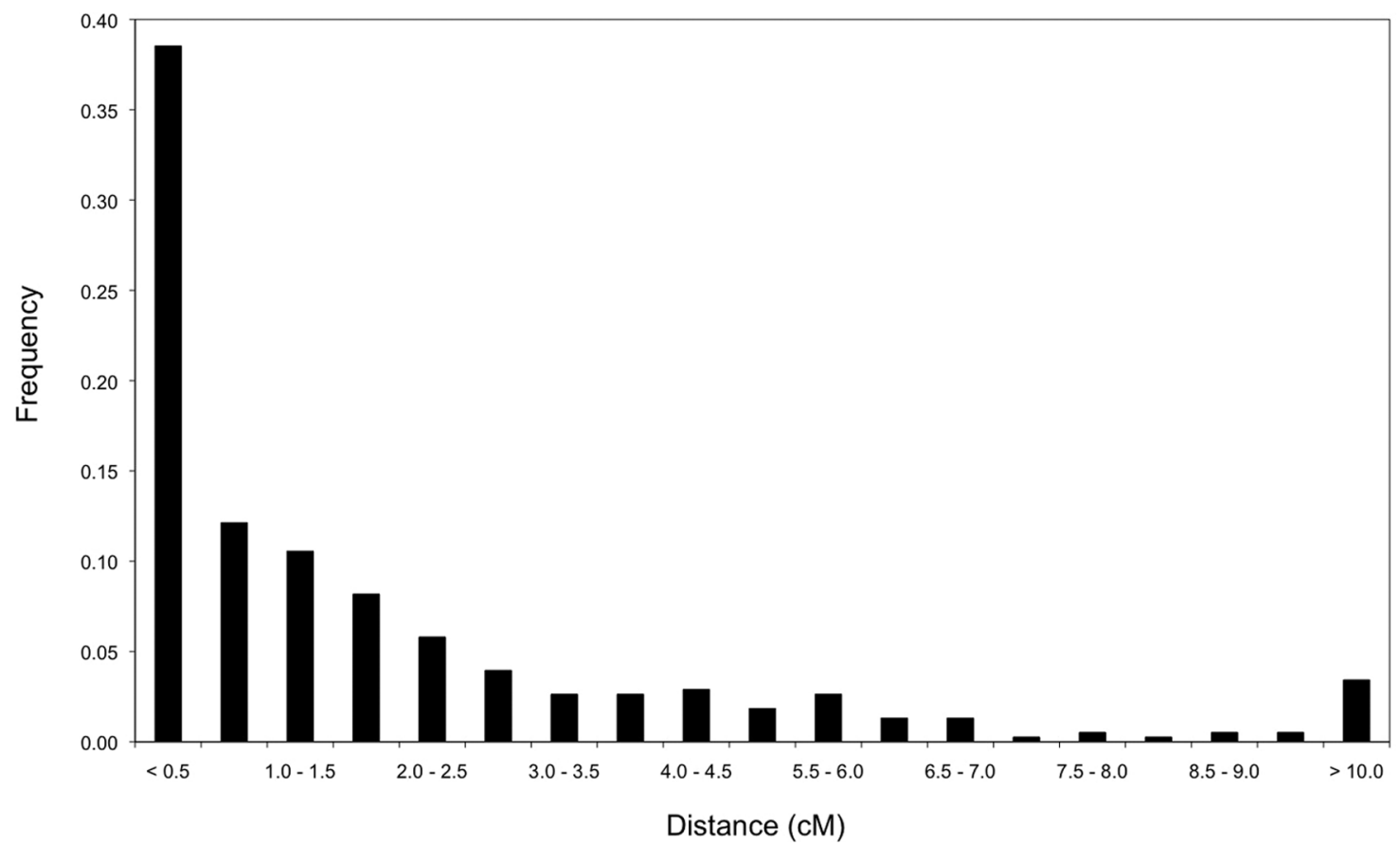

and Aegilops in a short time period of about 3 weeks. Such medium-density maps can be useful for mapping and tagging target genes as was done for the leaf rust resistance gene in this study and thanks to availability of sequences from the mapped DArT markers the initiation of targeted, higher resolution mapping. This study clearly demonstrates the rapid, economical utility of DArT for genotyping uncharacterized species where pertinent genomic information is lacking. Previous to this study, genetic linkage maps had only been developed for the Sitopsis species of Ae. speltoides (Luo et al. 2005) and Ae. longissima (Zhang et al. 2001) using RFLP markers.

The Ae. sharonensis linkage map consisted of 10 linkage groups with a total genetic length of $818.0 \mathrm{cM}$ (Table 2). The average size of the linkage groups was $81.8 \mathrm{cM}$, with a range of $2.3-124.6 \mathrm{cM}$. The linkage groups reported here for Ae. sharonensis are smaller than those reported for the 624 (DArT, AFLP, and SSR markers) (Semagn et al. 2006) and 1235 (SSR markers) (Somers et al. 2004) markerbased linkage maps of T. aestivum, which ranged from 60 to $180 \mathrm{cM}$. With respect to marker density, however, the value found for the
Ae. sharonensis map ( $2.52 \mathrm{cM} /$ loci excluding linkage group J) was comparable to that reported for the wheat consensus map $(2.2 \mathrm{cM})$ (Somers et al. 2004). Yet the frequency (39\%) of DArT markers identified with linkage distances shorter than $0.5 \mathrm{cM}$ was lower than those observed in bread wheat (51\%) (Semagn et al. 2006). Luo et al. (2005) indicated that reductions in the overall length of an Ae. speltoides RFLP map in comparison to that of Triticum monococcum were due to differences in the frequency and location of chromosomal recombination. As differences in crossover distribution have been reported among the T. monococcum, Ae. Speltoides, and Ae. longissima genomes (Zhang et al. 2001; Luo et al. 2005), it is certainly possible that the same phenomenon may be responsible for the differences observed in map sizes between the species. Reduced map sizes also may be caused by inadequate marker coverage in some distal regions of the individual Ae. sharonensis chromosomes. The mapping of additional markers (be they SSR or SNP) located in distal regions of wheat chromosomes will be useful for testing this hypothesis. Although a good medium-density map was constructed using DArT and SSR markers in this study, 
several significant gaps ranging from 10 to $24.1 \mathrm{cM}$ were still observed in some linkage groups (Table 2). These gaps may have resulted from inadequate marker coverage or the presence of high recombination in specific gene-rich regions of the chromosomes. High recombination in gene-rich regions was previously reported in bread wheat and barley (Gill et al. 1996; Sandhu et al. 2001; Weng and Lazar 2002). The recent development of a 90K SNP platform for wheat (Eduard Akhunov, personal communication) and other high density genome profiling technologies based on Genotyping by Sequencing concepts (e.g., DArTseq offered by DArT PL) will provide a powerful new tool for obtaining highly dense genomic maps of allied species like Ae. sharonensis.

Based on previous information regarding the chromosomal location of 103 DArT and 12 SSR markers in the wheat genome and the homoeologous relationship between the chromosomes of Ae. sharonensis and T. aestivum, we attempted to assign the linkage groups generated in this study to individual Ae. sharonensis chromosomes $\left(\mathrm{S}^{\mathrm{sh}}\right)$ found homoeologous to wheat via a cytogenetics approach. The homoeologous relationship between Ae. sharonensis and T. aestivum was first described by C-banding analysis (Friebe and Gill 1996; Maestra and Naranjo 1997). These studies found a normal homoeologous relationship for all of the $S^{\text {sh }}$ chromosomes to bread wheat and without any apparent chromosome rearrangements in Ae. sharonensis relative to wheat. Maestra and Naranjo (1997) also observed a close relationship between the $S^{\text {sh }}$ genome and $\mathrm{B}$ genome of wheat. In this study, we were able to assign linkage groups $\mathrm{A}, \mathrm{B}, \mathrm{C}$, and $\mathrm{E}$ to their respective $\mathrm{S}^{\text {sh }}$ chromosomes of $6 S^{\text {sh }}, 1 S^{\text {sh }}, 3 S^{\text {sh }}$, and $2 S^{\text {sh }}$ (Table 2). These individual linkage groups contained a predominance of loci with known chromosomal position in wheat and remained as consistent linkage groups (LOD > 6.0) during the development of the genetic map. The other six linkage groups could not be assigned with confidence to a specific $S^{\text {sh }}$ chromosome because of the presence of loci from different wheat chromosomes mapping to the same linkage group. The phenomenon of loci not mapping to homoeologous locations also was reported by Adonina et al. (2005) who studied the transferability of wheat SSRs to Aegilops species belonging to the Sitopsis. These authors considered nonhomoeologous loci to correspond to segmental duplications through association with retrotransposons. The inclusion of additional markers (i.e., SSR or SNP) in these linkage groups will be necessary to assign, with greater certainty, the linkage groups to homoeologous chromosomes and provide further evidence for chromosome rearrangements.

Two linkage groups (D and G) had groups of loci previously located in distal regions of different chromosome arms of wheat (Fig. 1). Chromosome inversions and translocations have been reported as major causes for the alteration of marker order in Ae. tauschii (Boyko et al. 1999) and Ae. speltoides (Luo et al. 2005) relative to bread wheat. Reciprocal translocations involving whole arms of chromosomes $1 S^{\text {sh }}$ and $2 S^{\text {sh }}$ of Ae. sharonensis were reported by Friebe and Gill (1996). The occurrence of translocations between arms of different Ae. sharonensis chromosomes may be one explanation for groups of loci from different wheat chromosomes occurring in the same Ae. sharonensis linkage group. In this regard, an interesting case occurred in linkage group D, where 14 loci from wheat chromosome $4 \mathrm{~A}$ mapped across one chromosome arm. This is the only case where a large number of markers from a genome other than B of wheat appeared clustered in an Ae. sharonensis linkage group. Adonina et al. (2005) reported that a high frequency of markers from the A and D genomes of wheat amplified the genomes of Aegilops species in the Sitopsis (Ae. longissima, Ae. speltoides, and Ae. searsii). The authors suggested that this phenomenon could be due to the ancient origin of these DNA regions. The region of linkage group D containing 14 clustered loci from wheat chromosome $4 \mathrm{~A}$ may be the result of a conserved region between the $\mathrm{A}$ and $\mathrm{B}$ genomes.
Aegilops longissima, a closely related species to Ae. sharonensis, carries a reciprocal translocation between the distal regions of chromosomes arms $4 S^{1}$ and $7 S^{1}$ (Friebe et al. 1993). This translocation was not found in the remaining four species of the Sitopsis, including Ae. sharonensis (Miller et al. 1982; Maestra and Naranjo 1997; Zhang et al. 2001). However, we observed in opposite "arms" of linkage group $\mathrm{D}$, a region of 14 loci from wheat chromosome $4 \mathrm{~A}$ and a region of 10 loci from wheat chromosome 7B (Fig. 1). Although we cannot confirm the presence of a 4/7 reciprocal translocation until the seven linkage groups are assigned to the homoeologous chromosomes in wheat, these results suggest that the accessions used to develop the linkage map (1644 and 1193) may carry the translocation. Aegilops sharonensis and Ae. longissima are sympatric species, and morphological intermediate types and hybrids have been found in mixed populations (Eig 1928; Ankori and Zohary 1962; Millet et al. 2006). It is possible that one of the accessions used as a parent of the cross is the result of an interspecific hybridization between Ae. sharonensis and Ae. longissima.

Loci exhibiting segregation distortion were observed in seven linkage groups. Most of the loci with skewed segregation appeared to be dispersed across the linkage groups with the exception of those from linkage group C. Several regions with distorted segregating loci in linkage group C (chromosome $3 S^{\text {sh }}$ ) were observed, and all favored the alleles from the female parent (1193). Deviations from the expected Mendelian segregation ratios of genetic markers and regions with skewed segregation ratios have been reported in Ae. tauschii (Faris et al. 1998; Boyko et al. 1999) and cereals such as barley (Kleinhofs et al. 1993), rice (Xu et al. 1997), and bread wheat (Semagn et al. 2006). Faris et al. (1998) suggested that the regions with skewed segregation ratios in Ae. tauschii may carry genetic selection factors for gametophyte competition or genes for hybrid sterility.

The first genetic linkage map of Ae. sharonensis was developed in this study and facilitated the mapping of a leaf rust resistance gene to a specific region in chromosome $6 S^{\text {sh }}$ (linkage group A) in accession 1644. This gene may be useful in agriculture because it confers resistance to the common, highly virulent leaf rust race THBJ in the USA. It is also effective against races PNMQ and BBBB (Olivera et al. 2007). Introgressing resistance genes from Ae. sharonensis into wheat is not trivial because it involves special cytogenetic techniques and dealing with gametocidal genes that control the preferential transmission of certain chromosomes (Olivera and Steffenson 2009). Additionally, as with all exotic sources of resistance, linkage drag can be a problem. Still, a number of researchers have successfully transferred genes from this species into wheat (Olivera and Steffenson 2009). Marais et al. (2006) reported the introgression of a leaf rust and stripe rust resistance gene from Ae. sharonensis into chromosome $6 \mathrm{~A}$ of cultivated wheat. Based on telosomic and SSR analysis, the authors were able to identify that the leaf rust resistance gene was introgressed through a crossover between the long arms of chromosome $6 \mathrm{~A}$ of wheat and $6 \mathrm{~S}^{\text {sh }}$ of Ae. sharonensis. However, no SSR markers linked with the genes were reported by the authors. A gene postulation study using a large collection of $P$. triticina races will be required to determine whether the leaf rust resistance gene reported by Marais et al. (2003) is the same as the one reported in this study. Alternatively, an allelism test could be conducted between the respective sources of resistance. Previously, Marais et al. (2003) found that wheat lines carrying the introgressed chromosome arm from Ae. sharonensis were highly resistant to leaf rust and stripe rust, but susceptible to stem rust. Although no co-segregating markers were found for the leaf rust resistance gene LrAeSh1644 in this study, it was tagged by markers just a short distance away. The leaf rust resistance gene mapped just $1.9 \mathrm{cM}$ away from the closest linked DArT marker wpt-9881. If these DArT markers can be successfully converted into breeder friendly markers, their close linkage will facilitate the introgression of these resistance genes into cultivated wheat. 
The genomics revolution will certainly allow researches to more efficiently exploit the variation locked up in wild crop species. A large scale genomics project for Ae. sharonensis was recently initiated by the Two Blades Project at the Sainsbury Laboratory in Norwich, UK, under the direction of Jonathan Jones (Champouret et al. 2011). The primary goal of this project is to clone a number of genes conferring resistance to African stem rust (e.g., race TTKSK) from the wild species and insert them as cassettes into wheat with the hope of increasing the longevity of resistance. In addition to leaf rust, accession 1644 also is resistant to African stem rust race TTKSK (Olivera et al. 2007). The genome of 1644 was recently sequenced and is currently being annotated. This information, together with other genomic resources being developed for Ae. sharonensis, will facilitate the cloning of both stem rust and leaf rust resistance genes in accession 1644. The transfer of resistance genes via transformation will overcome any problems associated with linkage drag and gametocidal genes.

\section{Acknowledgements}

This research was funded in part by the Lieberman-Okinow Endowment at the University of Minnesota. We thank J. Kolmer for providing leaf rust culture and D. Garvin for providing wheat microsatellite primers.

\section{References}

Adonina, I.G., Salina, E.A., Pestsova, E.G., and Röder, M.S. 2005. Transferability of wheat microsatellites to diploid Aegilops species and determination of chromosomal localizations of microsatellites in the $S$ genome. Genome, 48(6): 959-970. doi:10.1139/g05-072. PMID:16391665.

Akbari, M., Wenzl, P., Caig, V., Carling, J., Xia, L., Yang, S., et al. 2006. Diversity arrays technology (DArT) for high-throughput profiling of the hexaploid wheat genome. Theor. Appl. Genet. 113: 1409-1420. doi:10.1007/s00122-0060365-4. PMID:17033786.

Anikster, Y., Manisterski, J., Long, D.L., and Leonard, K.J. 2005. Resistance to leaf rust, stripe rust, and stem rust in Aegilops spp. in Israel. Plant Dis. 89: 303-308. doi:10.1094/PD-89-0303.

Ankori, H., and Zohary, D. 1962. Natural hybridization between Aegilops sharonensis and Ae. longissima: a morphological and cytological study. Cytologia, (Tokyo), 27: 314-324. doi:10.1508/cytologia.27.314.

Boyko, E.V., Gill, K.S., Mickelson-Young, L., Nasuda, S., Raupp, W.J., Ziegle, J.N., et al. 1999. A high-density genetic linkage map of Aegilops tauschii, the D-genome donor of bread wheat. Theor. Appl. Genet. 99: 16-26. doi:10.1007| s001220051204.

Champouret, N., Moscou, M., Bouyioukos, C., Hernandez-Pinzon, I., Olivera, P., Steffenson, B., et al. 2011. Using a wild relative to tackle stem rust race Ug99. In Proceedings Borlaug Global Rust Initiative 2011 Technical Workshop. Edited by R. McIntosh. St. Paul, MN. pp. 180.

Doyle, J.J., and Doyle, J.L. 1990. Isolation of plant DNA from fresh tissue. Focus, 12: 13-15.

Eig, A. 1928. Aegilops sharonensis n. sp. Notizbl. Bot. Gart. Mus. Berlin. Band, 10: 490-491.

Faris, J.D., Laddomada, B., and Gill, B.S. 1998. Molecular mapping of segregation distortion loci in Aegilops tauschii. Genetics, 149: 319-327. PMID:9584106.

Friebe, B., and Gill, B.S. 1996. Chromosome banding and genome analysis in diploid and cultivated polyploid wheats. In Methods of genome analysis in plants. Edited by P.P. Jauhar. CRC Press, Boca Raton. pp. 39-60.

Friebe, B., Tuleen, N., Jiang, J., and Gill, B.S. 1993. Standard karyotype of Triticum longissimum and its cytogenetic relationship with T. aestivum. Genome, 36(4): 731-742. doi:10.1139/g93-098.

Gill, B.S., Sharma, H.C., Raupp, W.J., Browder, L.E., Hatchett, J.H., Harvey, T.L., et al. 1985. Evaluation of Aegilops species for resistance to wheat powdery mildew, wheat leaf rust, Hessian fly and greenbug. Plant Dis. 69: 314-316.

Gill, K.S., Gill, B.S., Endo, T.R., and Boyko, E.V. 1996. Identification of highdensity mapping of gene-rich regions in chromosome group 5 of wheat. Genetics, 143: 1001-1012. PMID:8725245.

Gupta, P.K., Balyan, H.S., Edwards, K.J., Isaac, P., Korzun, V., Röder, M., et al. 2002. Genetic mapping of 66 new microsatellite (SSR) loci in bread wheat. Theor. Appl.Genet. 105: 413-422.

Hanson, W.D. 1958. Minimum family sizes for the planning of genetic experiments. Agron. J. 51: 711-715. doi:10.2134/agronj1959.00021962005100120005x.

Hernández, P., Laurie, D.A., Martín, A., and Snape, J.W. 2002. Utility of barley and wheat simple sequence repeat (SSR) markers for genetic analysis of Hordeum chilense and tritordeum. Theor. Appl. Genet. 104: 735-739. doi:10.1007/ s001220100674. PMID:12582681.

Jaccoud, D., Peng, K., Feinstein, D., and Kilian, A. 2001. Diversity arrays: a solid state technology for sequence information independent genotyping. Nucleic Acids Res. 29: e25. doi:10.1093/nar/29.4.e25. PMID:11160945.
Kimber, G., and Feldman, M. 1987. Wild wheat - an introduction. Special Report 353, College of Agriculture, University of Missouri, Columbia, USA.

Kleinhofs, A., Kilian, A., Saghai Maroof, M.A., Biyashev, R.M., Hayes, P., Chen, F.Q., et al. 1993. A molecular, isozyme and morphological map of barley (Hordeum spontaneum) genome. Theor. Appl. Genet. 86: 705-712. doi:10. 1007/BF00222660.

Kolmer, J.A. 2005. Tracking wheat rust on a continental scale. Curr. Opin. Plant Biol. 8: 441-449. doi:10.1016/j.pbi.2005.05.001. PMID:15922652.

Kolmer, J.A., Long, D.L., and Hughes, M.E. 2004. Physiologic specialization of Puccinia triticina on wheat in the United States in 2002. Plant Dis. 88: 10791084. doi:10.1094/PDIS.2004.88.10.1079.

Kosambi, D.D. 1943. The estimation of map distances from recombination values. Ann. Eugen. 12: 172-175. doi:10.1111/j.1469-1809.1943.tb02321.x.

Long, D.L., and Kolmer, J.A. 1989. A North American system of nomenclature for Puccinia recondita f. sp. tritici. Phytopathology, 79: 525-529. doi:10.1094/Phyto79-525.

Long, D.L., Leonard, K.J., and Hughes, M.E. 2002. Virulence of Puccinia triticina on wheat in the United States in 1999. Plant Dis. 86: 15-19. doi:10.1094/PDIS.2002. 86.1.15.

Luo, M.-C., Deal, K.R., Yang, Z.-L., and Dvorak, J. 2005. Comparative genetic maps reveal extreme crossover localization in the Aegilops speltoides chromosomes. Theor. Appl. Genet. 111: 1098-1106. doi:10.1007/s00122-005-0035-y. PMID: 16088396.

Mace, E.S., Xia, L., Jordan, D.R., Halloran, K., Parh, D.K., Huttner, E., et al. 2008. DArT markers: diversity analyses and mapping in Sorghum bicolor. BMC Genomics, 9: 26. doi:10.1186/1471-2164-9-26. PMID:18208620.

Maestra, B., and Naranjo, T. 1997. Homoeologous relationships of Triticum sharonense chromosomes to T. aestivum. Theor. Appl. Genet. 94: 657-663. doi: $10.1007 / \mathrm{s} 001220050463$.

Manisterski, J., Segal, A., Levy, A.A., and Feldman, M. 1988. Evaluation of Israeli Aegilops and Agropyron species for resistance to wheat leaf rust. Plant Dis. 72: 941-944. doi:10.1094/PD-72-0941.

Mantovani, P., Maccaferri, M., Sanguineti, M.C., Tuberosa, R., Catizone, I., Wenzl, P., et al. 2008. An integrated DArT-SSR linkage map of durum wheat. Mol. Breed. 22: 629-648. doi:10.1007/s11032-008-9205-3.

Marais, G.F., Pretorius, Z.A., Marais, A.S., and Wellings, C.R. 2003. Transfer of rust resistance genes from Triticum species to common wheat. S. Afr. J. Plant Soil, 20: 193-198. doi:10.1080/02571862.2003.10634934.

Marais, G.F., McCallum, B., and Marais, A.S. 2006. Leaf rust and stripe rust resistance genes derived from Aegilops sharonensis. Euphytica, 149: 373-380. doi:10.1007/s10681-006-9092-9.

McCallum, B., Hiebert, C., Huerta-Espino, J., and Cloutier, S. 2012. Wheat leaf rust. In Disease resistance in wheat. Edited by I. Sharma. CAB International. Oxfordshire, U.K. pp. 33-62.

Miller, T.E., Hutchinson, J., and Chapman, V. 1982. Investigation of a preferentially transmitted Aegilops sharonensis chromosome in wheat. Theor. Appl. Genet. 61: 27-33. doi:10.1007/BF00261506.

Millet, E., Agami, M., Ezrati, S., Manisterski, J., and Anikster, Y. 2006. Distribution of Sharon goat grass (Aegilops sharonensis Eig) in Israel. Isr. J. Plant Sci. 54: 243-248. doi:10.1560/IJPS_54_3_243.

Miranda, L.M., Murphy, J.P., Marshall, D., and Leath, S. 2006. Pm34: a new powdery mildew resistance gene transferred from Ae. tauschii Coss. to common wheat (Triticum aestivum). Theor. Appl. Genet. 113: 1497-1504. PMID:16953419.

Oetting, W.S., Lee, H.K., Flanders, D.J., Wiesner, G.L., and Sellers, T.A. 1995. Linkage analysis with multiplexed short tandem repeat polymorphisms using infrared fluorescence and M13 tailed primers. Genomics, 30: 450-458. doi:10.1006/geno.1995.1264. PMID:8825630.

Olivera, P.D., and Steffenson, B.J. 2009. Aegilops sharonensis: origin, genetics, diversity, and potential for wheat improvement. Botany 87(8): 740-756. doi:10. 1139/B09-040.

Olivera, P.D., Kolmer, J.A., Anikster, Y., and Steffenson, B.J. 2007. Resistance of Sharon goatgrass (Aegilops sharonensis) to fungal diseases of wheat. Plant Dis. 91: 942-950. doi:10.1094/PDIS-91-8-0942.

Olivera, P.D., Millet, E., Anikster, Y., and Steffenson, B.J. 2008. Genetics of resistance to wheat leaf rust, stem rust, and powdery mildew in Aegilops sharonensis. Phytopathology, 98: 353-358. doi:10.1094/PHYTO-98-3-0353. PMID:18944087.

Plaschke, J., Ganal, M.W., and Röder, M.S. 1995. Detection of genetic diversity in closely related bread wheat using microsatellite markers. Theor. Appl. Genet. 91: 1001-1007. doi:10.1007/BF00223912.

Ramsay, L., Macaulay, M., Ivanissevich, S.D., Maclean, K., Cardle, L., Fuller, J., et al. 2000. A simple sequence repeat-based linkage map of barley. Genetics, 156: 1997-2005. PMID:11102390.

Röder, M., Korzun, V., Wendehake, K., Plaschke, J., Tixier, M.-H., Leroy, P., and Ganal, M.W. 1998. A microsatellite map of wheat. Genetics, 149: 2007-2023. PMID:9691054.

Sandhu, D., Champoux, J.A., Bondareva, S.N., and Gill, K.S. 2001. Identification and physical localization of useful genes and markers to major gene-rich region on wheat group 1S chromosomes. Genetics, 157: 1735-1747. PMID: 11290727.

Semagn, K., Bjørnstad, Å., Skinnes, H., Marøy, A.G., Tarkegne, Y., and William, M. 2006. Distribution of DArT, AFLP, and SSR markers in a genetic 
linkage map of a doubled-haploid hexaploid wheat population. Genome, 49(5): 545-555. doi:10.1139/g06-002. PMID:16767179.

Somers, D.J., Isaac, P., and Edwards, K. 2004. A high-density microsatellite consensus map for bread wheat (Triticum aestivum L.). Theor. Appl. Genet. 109: 1105-1114. doi:10.1007/s00122-004-1740-7. PMID:15490101.

Song, Q.J., Fickus, E.W., and Cregan, P.B. 2002. Characterization of trinucleotide SSR motifs in wheat. Theor. Appl. Genet. 104: 286-293. doi:10.1007/ s001220100698. PMID:12582699.

Tanksley, S.D., and McCouch, S.R. 1997. Seed banks and molecular maps: unlocking genetic potential from the wild. Science, 277: 1063-1066. doi:10.1126/ science.277.5329.1063. PMID:9262467.

Tinker, N.A., Kilian, A., Wight, C.P., Heller-Uszynska, K., Wenzl, P., Rines, H.W., et al. 2009. New DArT markers for oat provide enhanced map coverage and global germplasm characterization. BMC Genomics, 10: 39. doi:10.1186/14712164-10-39. PMID:19159465.

van Ooijen, J.W. 2006. JoinMap Version 4.0, software for the calculation of genetic linkage maps. Kyazma B.V., Wageningen, the Netherlands.

van Slageren, M.W. 1994. Wild wheats: a monograph of Aegilops L. and Amblyopyrum (Jaub. \& Spach) Eig (Poaceae). Agricultural University Wageningen: the Netherlands; ICARDA: Aleppo, Syria.

Varshney, R.K., Sigmund, R., Börner, A., Korzun, V., Stein, N., Sorrells, M.E., et al. 2005. Interspecific transferability and comparative mapping of barley ESTSSR markers in wheat, rye and rice. Plant Sci. 168: 195-202. doi:10.1016/j. plantsci.2004.08.001.
Voorrips, R.E. 2002. MapChart: software for the graphical presentation of linkage maps and QTLs. J. Hered. 93: 77-78. doi:10.1093/jhered/93.1.77. PMID: 12011185.

Warham, E.J., Mujeeb-Kazi, A., and Rosas, V. 1986. Karnal bunt (Tillietia indica) resistance screening of Aegilops species and their practical utilization in Triticum aestivum improvement. Can. J. Plant Pathol. 8(1): 65-70. doi:10.1080/ 07060668609501844.

Weng, Y., and Lazar, M.D. 2002. Comparison of homoeologous group-6 short arm physical maps of wheat and barley reveals a similar distribution of recombinogenic and gene-rich regions. Theor. Appl. Genet. 104: 1078-1085. doi:10.1007/s00122-001-0804-1. PMID:12582615.

Wenzl, P., Carling, J., Kudrna, D., Jaccoud, D., Huttner, E., Kleinhofs, A., and Kilian, A. 2004. Diversity arrays technology (DArT) for whole-genome profiling of barley. Proc. Natl. Acad. Sci. U.S.A. 101: 9915-9920. doi:10.1073/pnas. 0401076101. PMID:15192146.

Xu, Y, Zhu, L., Xiao, J., Huang, N., and McCouch, S.R. 1997. Chromosomal regions associated with segregation distortion of molecular markers in $\mathrm{F}_{2}$, backcross, double haploid, and recombinant inbred populations in rice (Oryza sativa L.). Mol. Gen. Genet. 253: 535-545. doi:10.1007/s004380050355. PMID:9065686.

Zhang, H, Reader, S.M., Liu, X., Jia, J.Z., Gale, M.D., and Devos, K.M. 2001. Comparative genetic analysis of the Aegilops longissima and Ae. sharonensis genomes with common wheat. Theor. Appl. Genet. 103: 518-525. doi:10.1007/ s001220100656. 